\title{
Medievalista
}

\section{3.. Seminário Internacional - Imagens e Liturgia na Idade Média}

Carla Varela Fernandes

\section{(2) OpenEdition \\ 1 Journals}

\section{Edição electrónica}

URL: http://journals.openedition.org/medievalista/1300

DOI: $10.4000 /$ medievalista. 1300

ISSN: 1646-740X

\section{Editora}

Instituto de Estudos Medievais - FCSH-UNL

\section{Refêrencia eletrónica}

Carla Varela Fernandes, « 3. ${ }^{\circ}$ Seminário Internacional - Imagens e Liturgia na Idade Média », Medievalista [Online], 21 | 2017, posto online no dia 01 junho 2017, consultado o 23 setembro 2020. URL : http://journals.openedition.org/medievalista/1300 ; DOI : https://doi.org/10.4000/medievalista 1300

\section{(a) $(1)(9$}

Mediavalista está licenciado com uma Licença Creative Commons - Atribuição-NãoComercial 4.0 Internacional. 
Título: $3 .^{\circ}$ Seminário Internacional - Imagens e Liturgia na Idade Média

Autor(es) / Author(s): Carla Varela Fernandes

Universidade / University: Universidade Nova de Lisboa

Faculdade e Departamento / Unidade de Investigação - Faculty and Department /

Research Center: Faculdade de Ciênciais Sociais e Humanas, Instituto de Estudos

Medievais

Código Postal / Postcode: 1069-061

Cidade / City: Lisboa

País / Country: Portugal

Email Institucional / Institutional email: carlavfernandes@gmail.com

Fonte: Medievalista [Em linha]. Direc. Bernardo Vasconcelos e Sousa. Lisboa: IEM.

Disponível em:

http://www2.fcsh.unl.pt/iem/medievalista/MEDIEVALISTA21/fernandes2112.html ISSN: 1646-740X

Data de recepção do texto / Received for publication: 29 de Outubro de 2016 


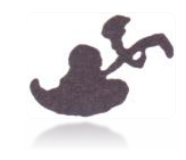

\section{3.o Seminário Internacional - Imagens e Liturgia na Idade Média}

\section{Carla Varela Fernandes}

Nos dias 20 e 21 de Outubro decorreu a terceira edição do Seminário Internacional de História da Arte - Imagens e Liturgia na Idade Média. A iniciativa, tal como em 2015, foi uma coorganização de três instituições, a fim de conjugar recursos e juntar sinergias: o Instituto de Estudos Medievais-FCSH/NOVA, o Secretariado Nacional para os Bens Culturais da Igreja (SNBCI) e o Museu Nacional de Arte Antiga (MNAA). Também o projecto científico “Movilidad y Transferencia Artística en el Mediterráneo (1187-1388) Artistas, Objetos y Modelos - MAGISTRI MEDITERRANEI” (MICINN: HAR201563883-P), da Universitat Autònoma de Barcelona, colaborou como instituição parceira, contando com a participação do seu director não só como orador de uma das conferências plenárias, mas também como membro da comissão científica do Seminário e do livro que lhe está associado e, ainda, com apoio financeiro. O Seminário contou também com o apoio financeiro da Fundação Calouste Gulbenkian.

Para esta terceira edição, foi constituída uma Comissão Científica (CC) que integrou reputados investigadores portugueses e estrangeiros (dos Estados Unidos da América, França, Espanha e Grécia), docentes ou investigadores de diferentes universidades, e conservadores / investigadores de museus com colecções de arte medieval. Na verdade, a CC espelha bem um dos princípios que nortearam desde o início a realização deste seminário sobre arte figurativa medieval: associar e fomentar a partilha de conhecimentos resultantes do trabalho científico produzido nas universidades e nos museus, espelhando, de alguma forma, a realidade da produção científica actual.

Desde o início (2014), o seminário tem por objectivo promover e divulgar os estudos sobre arte figurativa medieval (independentemente dos materiais ou técnicas) e tentar 
perceber a sua génese ou relação na praxis quotidiana com os rituais litúrgicos. Pretendeu-se a apresentação de estudos recentes, já concluídos ou em progresso, sobre temas distintos, que trouxessem novidade e, especialmente, debate para a comunidade científica e para o restante público interessado na História e no património medievais. O programa incluiu duas secções temáticas:

$1^{\text {a }}$ Seç̧ão: A difusão de imagens religiosas e a circulação de modelos e de artistas nos territórios atlânticos e mediterrânicos, The spread of religious images and the circulation of models and artists in the Atlantic and Mediterranean territories. Aqui, procurou-se potenciar a divulgação de estudos sobre arte ocidental no contacto com a arte bizantina, em especial as transferências artísticas entre Ocidente e Oriente. Contou com a participação de Manuel Castiñeiras González; Carla Varela Fernandes e Athanasios Semoglou.

2a Secção: Imagens/Espaços, Imagens/Textos e seu papel na liturgia e na devoção medievais, Images/spaces, images/texts and their role in medieval liturgy and devotion. Tratou-se de uma área temática com grande abrangência, que permitiu um maior número de participações, a saber: Alícia Miguélez Cavero, Joaquim Oliveira Caetano, Jordi Camps i Soria; Alessandra Bilotta; César Garcia de Castro Valdés; Francisco Moreno Martin; Luís Rêpas; Catarina Barreira; Ana Lemos.

Uma das conferências plenárias deste encontro - por Aires Augusto Nascimento - saiu do âmbito estrito das secções (ainda que na procura do entendimento da intrínseca relação das imagens com a liturgia) e constituiu uma reflexão profunda e muito pessoal sobre as diferentes formas (conjugadas com diferentes tempos) em que a Humanidade (através do pensamento e das mãos dos artistas) representou, ou tentou representar, o divino.

O programa incluiu também uma visita orientada às colecções de arte medieval do MNAA, no final do primeiro dia, realizada por dois dos conservadores / investigadores do museu - Maria João Vilhena de Carvalho e Joaquim Oliveira Caetano, incidindo sobre as questões mais relevantes que se prendem com obras selecionadas das colecções de escultura e pintura medievais deste museu (que conserva a maior colecção de arte medieval entre os museus portugueses). 
Se algo se pode concluir dos trabalhos realizados ao longo destes três anos é que esta é uma área temática que suscita forte interesse (como se verifica pela crescente adesão dos públicos de ano para ano) e que tem um vasto campo ainda por explorar. Ainda que a 3. ${ }^{\text {a }}$ edição constitua já a concretização de muitos dos objectivos iniciais deste projecto, há, claramente, espaço e interesse para continuar a promover encontros que aprofundem as relações entre a criação da arte figurativa e os rituais litúrgicos entre os séculos V e XV.

Tal como no seminário anterior, e em virtude da disponibilidade e vontade demonstradas pelo SNBCI, foi possível produzir e editar o livro com os textos de muitas das comunicação e conferências apresentadas nesses dias. Os textos das comunicações foram sujeitos previamente ao processo de peer review e para tal contámos com um grupo de investigadores que se disponibilizaram a fazer a revisão de cada texto num curtíssimo espaço de tempo. Esta publicação e a sua coincidência com os dias em que ainda decorrem os trabalhos constituem, sem dúvida, um dos grandes méritos deste encontro. A apresentação ocorreu no último dia do Seminário e foi realizada por Fernando António Baptista Pereira.

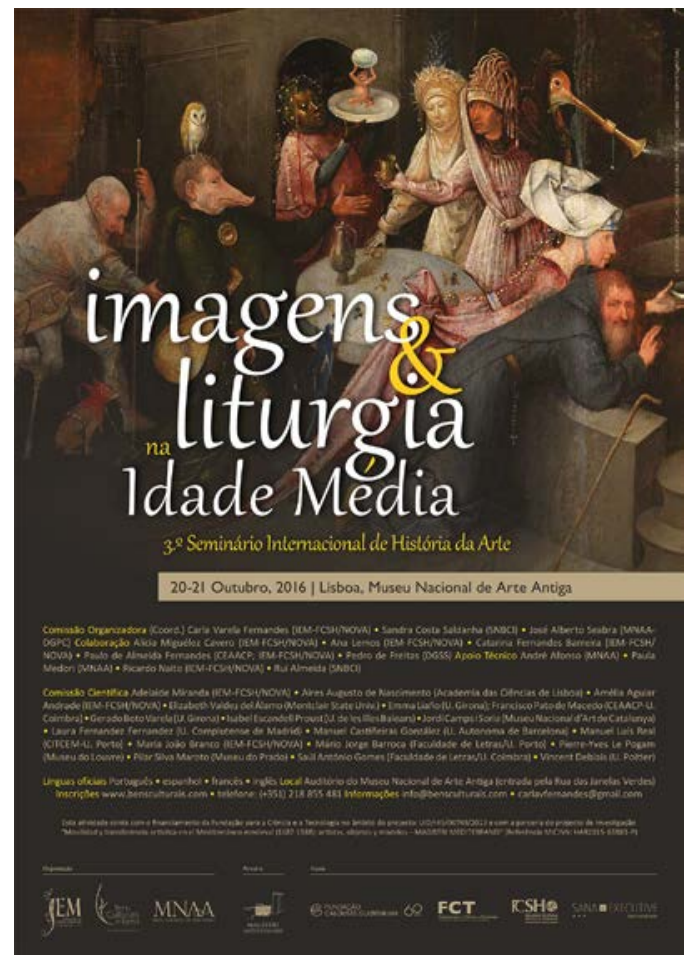

Figura 1 - Cartaz do Colóquio Imagens e Liturgia na Idade Média 


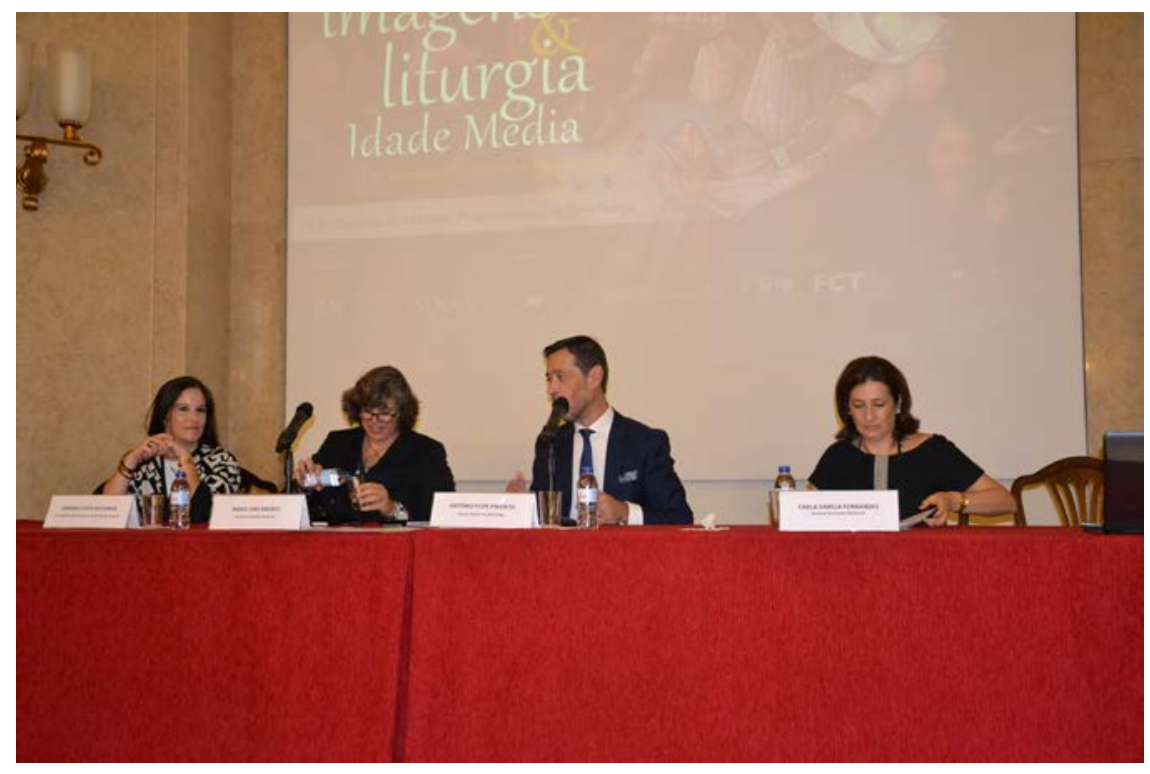

Figura 2 - Sessão de abertura do Colóquio Imagens e Liturgia na Idade Média

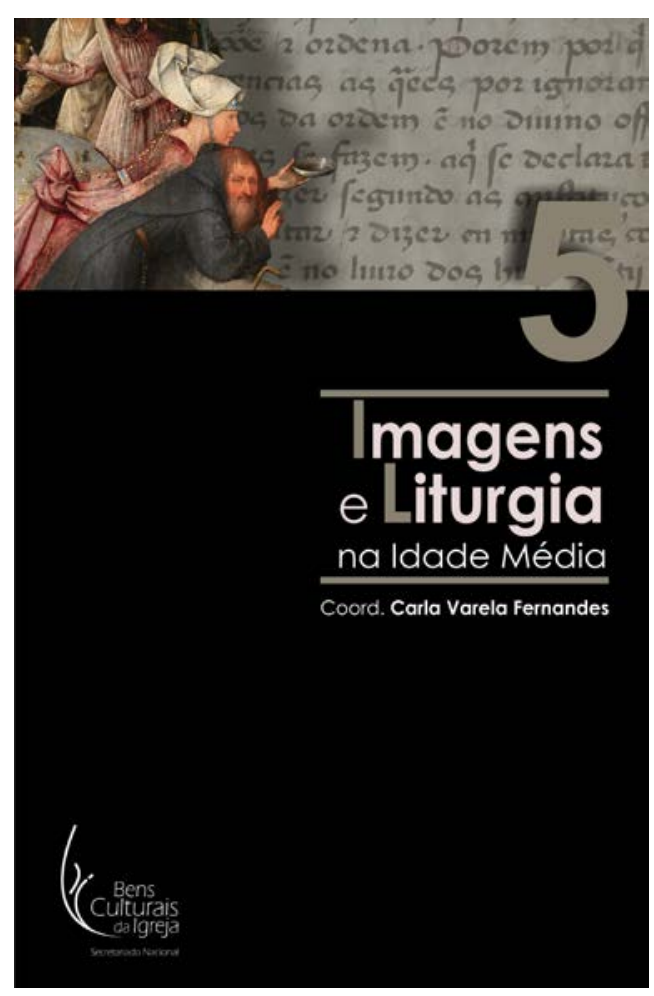

Figura 3 - Capa do livro lançado durante o Colóquio, Imagens e Liturgia na Idade Média, com coordenação de Carla Varela Fernandes 


\section{COMO CITAR ESTE ARTIGO}

\section{Referência electrónica:}

FERNANDES, Carla Varela - “3. ' Seminário Internacional - Imagens e Liturgia na Idade Média”. Medievalista 21 (Janeiro-Junho 2017). [Em linha] [Consultado dd.mm.aaaa]. Disponível em http://www2.fcsh.unl.pt/iem/medievalista/MEDIEVALISTA21/fernandes2112.html ISSN 1646-740X.

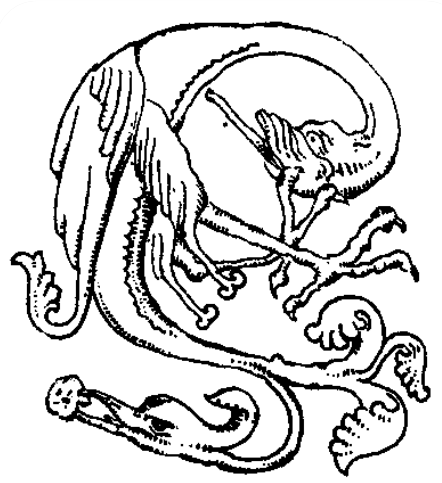

